\title{
DISCUSSION
}

\section{An experimental and theoretical comparison between static and dynamic torsional soil tests}

\author{
M. D. BOLTON and J. M. R. WILSON (1988). Géotechnique 39, No. 4, 585-599
}

F. Tatsuoka, S. Shibuya, S. Teachavorasinskun and C.S. Park, Institute of Industrial Science, University of Tokyo

It has been shown in the Paper that, for a range of shear strains between $0.0015 \%$ and $0.07 \%\left(1.5 \times 10^{-5}\right.$ and $\left.7 \times 10^{-4}\right)$ a remarkable similarity in terms of stiffness and damping characteristics of dry Leighton Buzzard sand was observed when it was subjected to cyclic loadings in two sets of apparatus; i.e. a resonant-column apparatus and a torsional shear apparatus. As referred in the Paper, a similar result concerning the stiffness of sand has been obtained by Iwasaki et al. (1978). The results of their tests spanned a range of strain from $0.004 \%$ to $0.04 \%$ (not from 0.04 to $0.4 \%$ as stated in the Paper), compared to $0.0015 \%$ to $0.07 \%$ in the Author's tests (see Table 2).

These test results suggest that dynamic tests on dry sands may be unnecessary and, at the same time, supported the status quo of current geotechnical engineering practice in Japan. Specifically dynamic analyses such as earthquake response analyses of ground or soil-structure systems require the evaluation of soil stiffness and damping for a range of strains from somewhere around $10^{-5}(0 \cdot 001 \%)$ to around $10^{-2}(1 \%)$. In this range of strains the dynamic deformation properties of various types of soils (e.g. saturated soft clays, saturated or dry sands, gravels, cementtreated soils and so on) are usually evaluated by performing quasi-static cyclic loading tests with a frequency of the order of $0.1 \mathrm{~Hz}$ (e.g. Kokusho, 1980), which are termed 'static' tests in the Paper. As a result of this the resonant-column tests have been less popular in Japan even for evaluating the dynamic properties at strain levels below $10^{-4}$.

Concerning maximum stiffness $G_{\max }$ at extremely small strains, a new torsional shear apparatus has been developed at our laboratory (Tatsuoka, 1988; Pradhan, et al., 1988; Teachavorasinskun, 1989; Tatsuoka et al., 1989) in which the accuracy of measuring stresses and strains has been substantially improved. Some typical results for the stiffness of Toyoura sand measured at a mean principal stress $p=\left(\sigma_{1}+\sigma_{2}+\sigma_{3}\right) / 3$ of $98 \mathrm{kN} / \mathrm{m}^{2}$ are shown in Fig. 13. These results have been obtained from a monotonic loading torsional simple shear (ML TSS) test for an initial void ratio of 0.69 and a static cyclic loading torsional simple shear (SCL TSS) test for an initial void ratio of 0.66 . Also shown in Fig. 13 are the average curves obtained from several resonantcolumn (RC) tests and static cyclic loading torsional shear (SCL TS) tests for void ratios of 0.70 (curve 3) and 0.66 (curve 4) (Iwasaki et al., 1978). It is clear from Fig. 13 that for strains below $10^{-4}$ the shear moduli from the RC tests (curves 3 and 4) and those from the SCL TS tests (curve 2) are very similar, now spanning a range of strain from around $0.001 \%\left(10^{-5}\right)$ to around $0.04 \%$ $\left(4 \times 10^{-4}\right)$. The stress-strain relationship of another MLTSS test is shown in Fig. 14, in which data is plotted for maximum scales of shear strain of $10 \%\left(10^{-1}\right)$ and $0.01 \%\left(10^{-4}\right)$. It may be seen from curve $B$ that the initial shear modulus $G_{\max }$ could well be defined from the initial linear portion of shear strains below $0.001 \%\left(10^{-5}\right)$. It may also be noted that the value of $G_{\max }$ is similar to the secant modulus of a small unloading-reloading hysteresis loop with a single amplitude strain of the order of $10^{-5}$.

In Fig. 13 the value of $G_{\max }$ from the MLTSS test (curve 1) is similar to those of the corresponding RC tests (curves 3 and 4) and of the SCL TS test (curve 2). The coincidence of $G_{\max }$ between monotonic and cyclic loading tests has been observed for other types of sand, gravel and a cement-treated sandy soil as sheared in torsional shear, in plane strain compression and in triaxial compression (Shibuya et al., 1990). A practical implication of the coincidence of $G_{\max }$ amongst these various testing methods is that $G_{\max }$ under dynamic loading conditions can be evaluated even by monotonic loading tests.

Some laboratory tests have been performed on silver Leighton Buzzard sand, as used by Wong and Arthur (1985), at the Institute of Industrial Science. Fig. 15 shows the results of the tests in which Leighton Buzzard sand was sheared in monotonic loading plane strain compression (ML PSC test). The specimens were $20 \mathrm{~cm}$ high, $8 \mathrm{~cm}$ wide in the $\sigma_{3}$ direction and $16 \mathrm{~cm}$ long and were prepared by the air-pluviation method. The initial void ratio of the specimen measured at a confining pressure of $5 \mathrm{kN} / \mathrm{m}^{2}$ was around 0.56 . The confining pressure applied was $78.4 \mathrm{kN} / \mathrm{m}^{2}$. The axial and lateral strains were measured 
Table 2. Testing conditions of $\mathrm{RC}$ and SCL TS tests

\begin{tabular}{|c|c|c|c|}
\hline & Bolton \& Wilson (1989) & Iwasaki et al. (1978) & Tatsuoka et al. \\
\hline Sand & $\begin{array}{l}\text { Dry Leighton } \\
\text { Buzzard sand, } \\
\text { preparation } \\
\text { method unknown }\end{array}$ & $\begin{array}{l}\text { Air-dried and } \\
\text { saturated Toyoura } \\
\text { sand prepared by } \\
\text { various methods } \\
\text { including air pluviation }\end{array}$ & $\begin{array}{l}\text { Saturated Toyoura } \\
\text { sand prepared by } \\
\text { air pluviation }\end{array}$ \\
\hline $\begin{array}{l}\text { Shape and } \\
\text { dimensions of } \\
\text { sample: } \mathrm{mm}^{*}\end{array}$ & $\begin{array}{l}\text { RC and SCL: } \\
\text { solid cylinder } \\
38 \mathrm{D} \text { and } 78 \mathrm{H}\end{array}$ & $\begin{array}{l}\text { Hollow cylinder } \\
\text { RC: } 100 \mathrm{OD}, 60 \mathrm{ID} \\
\text { and } 250 \mathrm{H} \\
\text { SCL: } 100 \mathrm{OD}, 60 \mathrm{ID} \\
\text { and } 100 \mathrm{H}\end{array}$ & $\begin{array}{l}\text { Hollow cylinder } \\
\text { SCL: } 100 \mathrm{OD}, 60 \mathrm{ID} \\
\text { and } 200 \mathrm{H}\end{array}$ \\
\hline $\begin{array}{l}\text { Preshearing } \\
\text { in } \mathrm{RC} \text { for } \mathrm{SCL}\end{array}$ & None & None & None \\
\hline $\begin{array}{l}\text { Prestressing } \\
(\mathrm{NC} \text { or } \mathrm{OC}) \dagger\end{array}$ & $\begin{array}{l}\text { No (normally } \\
\text { consolidated) }\end{array}$ & $\begin{array}{l}\text { No (normally } \\
\text { consolidated) }\end{array}$ & $\begin{array}{l}\text { Yes and no } \\
\text { (no for the data } \\
\text { presented here) }\end{array}$ \\
\hline $\begin{array}{l}\text { Consolidation } \\
\text { stress }\end{array}$ & Isotropic & $\begin{array}{l}\text { Anisotropic and } \\
\text { isotropic (isotropic } \\
\text { for the data } \\
\text { presented here) }\end{array}$ & $\begin{array}{l}\text { Anisotropic and } \\
\text { isotropic (anisotropic } \\
\text { for the data } \\
\text { presented here) }\end{array}$ \\
\hline Shearing mode & $\begin{array}{l}\text { Pure shear at } \\
\text { constant } \sigma_{a} \\
\text { and } \sigma_{r} \dagger\end{array}$ & $\begin{array}{l}\text { Pure shear at } \\
\text { constant } \sigma_{\mathrm{a}} \\
\text { and } \sigma_{\mathrm{r}} \dagger\end{array}$ & $\begin{array}{l}\text { Simple shear at a } \\
\text { constant } \sigma_{\mathrm{a}} \text { and } \\
\text { constant areas and } \\
\text { shapes of horizontal } \\
\text { planes }\end{array}$ \\
\hline $\begin{array}{l}\text { Cyclic loading } \\
\text { method in SC } \\
\text { test }\end{array}$ & $\begin{array}{l}\text { Strain-controlled, at a } \\
\text { constant shear } \\
\text { stress amplitude } \\
f=0.001 \mathrm{~Hz}\end{array}$ & $\begin{array}{l}\text { Stress-controlled at a } \\
\text { constant shear } \\
\text { stress amplitude } \\
f=0.1 \mathrm{~Hz}\end{array}$ & $\begin{array}{l}\text { Strain-controlled at a } \\
\text { constant shear } \\
\text { stress amplitude } \\
\mathrm{d} \gamma / \mathrm{d} t=0.01 \% / \mathrm{min}\end{array}$ \\
\hline $\begin{array}{l}\text { Strain range } \\
\text { spanned }\end{array}$ & $0.0015 \%-0.07 \%$ & $0.004 \%-0.04 \%$ & Only SCL, $0.001->0.1 \%$ \\
\hline $\begin{array}{l}\text { No. of cycles } \\
\text { for } G_{\text {sec }} \text { in SC }\end{array}$ & $\begin{array}{l}\text { Not specified, at the } \\
\text { steady state }\end{array}$ & Tenth cycle & Fifth cycle \\
\hline
\end{tabular}

locally on the two lateral surfaces ( $\sigma_{3}$ planes) of the specimen. The axial strain free from bedding error at the top and bottom ends of the specimen were measured by using a device called local deformation transducer (Tatsuoka, 1988; Tatsuoka et al., 1990). The lateral strain was measured by using four proximeters for each surface. With this instrumentation the lateral strain could be measured precisely until the formation of the shear band(s) (see Fig. 15(a)). The small strain behaviour is shown in Fig. 15(b). In these tests, the fixed angles $\delta$, the direction of $\sigma_{1}$ relative to the bedding plane, were changed at values of $0^{\circ}$, $25^{\circ}$ and $90^{\circ}$. It can be seen from Fig. 15 that $G_{\max }$ is independent of $\delta$, while $\phi=\arcsin \left[\left(\sigma_{1}-\sigma_{3}\right) b /\right.$ $\left.\left(\sigma_{1}+\sigma_{3}\right)\right]_{\max }$ is strongly dependent on $\delta$.
From the initial slope $\mathrm{d} T / \mathrm{d} \gamma$ of each relationship between the torque and the shear strain at the circumference as shown in Fig. 2, the value of $G_{\max }$ can be obtained from the Authors results; e.g. for dynamic test 2 (initial void 0.558 and confining pressure $p=93 \mathrm{kN} / \mathrm{m}^{2}$ ), a value of $(\mathrm{dT} / \mathrm{d} \gamma)_{\text {initial }}$ is approximately $2.27 \times 10^{4} \mathrm{Nm}$. By using

$$
(\mathrm{d} T / \mathrm{d} \gamma)_{\text {initial }}=G_{\max } \pi r_{0}{ }^{3} / 2
$$

where $r_{0}$ is the radius of the specimen $(1.9 \mathrm{~cm})$, the valued of $G_{\max }$ is $2.1 \times 10^{5} \mathrm{kN} / \mathrm{m}^{2}$. This value for $G_{\max }$ is then corrected to match the conditions of our PSC tests. By assuming that

$$
G_{\max } \propto p^{0.4}(2 \cdot 17-e)^{2} /(1+e)
$$




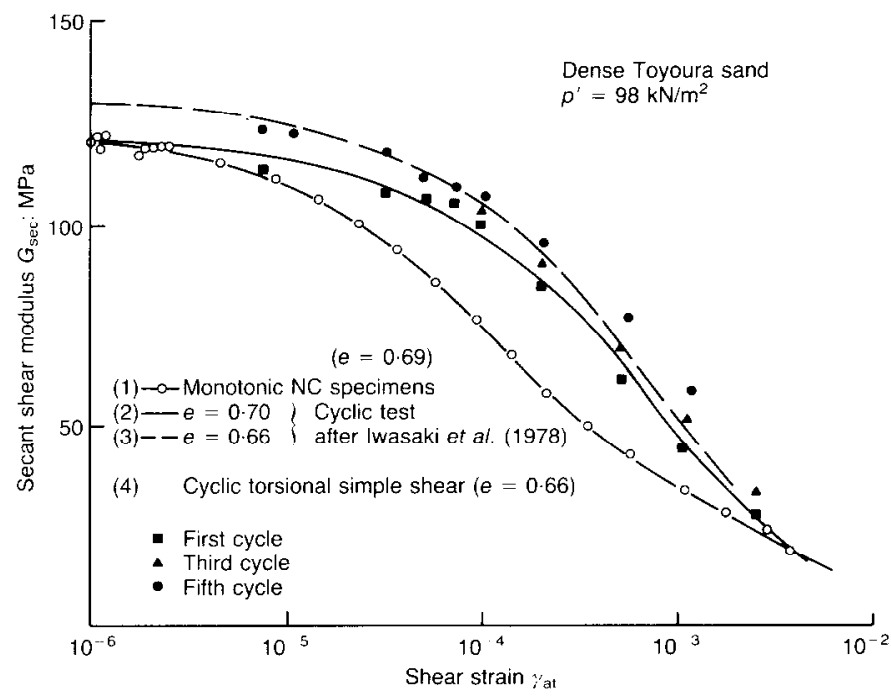

Fig. 13. Shear modulus-shear strain relationships (see Table 2): 1 ML TSS test, 2 SCL TSS test, 3 and 4 average from RC tests and SCL TS tests by Iwasaki et al. (1978)

the corrected value of $G_{\max }$ is $1.97 \times 10^{5} \mathrm{kN} / \mathrm{m}^{2}$, which is indicated in Figs 15(b) and 16. It may be seen that the value of $G_{\max }$ from the Authors' RC test practically coincides with that of our PSC test at $\delta=90^{\circ}$. The difference in $\delta$ between these two tests ( $c f . \delta= \pm 45^{\circ}$ in RC test) is not significant since $G_{\max }$ is hardly affected by $\delta$. Accordingly, like Toyoura sand, it is suggested that the initial modulus of the Leighton Buzzard sand could also be evaluated from a static monotonic loading test.

In Fig. 3 the stress-strain relation in the first loading is presented. While it is not clear whether or not this specimen had previously shown strain, it is interesting that when $G_{\max }$ is determined from the initially linear portion of an $M L$ test on a

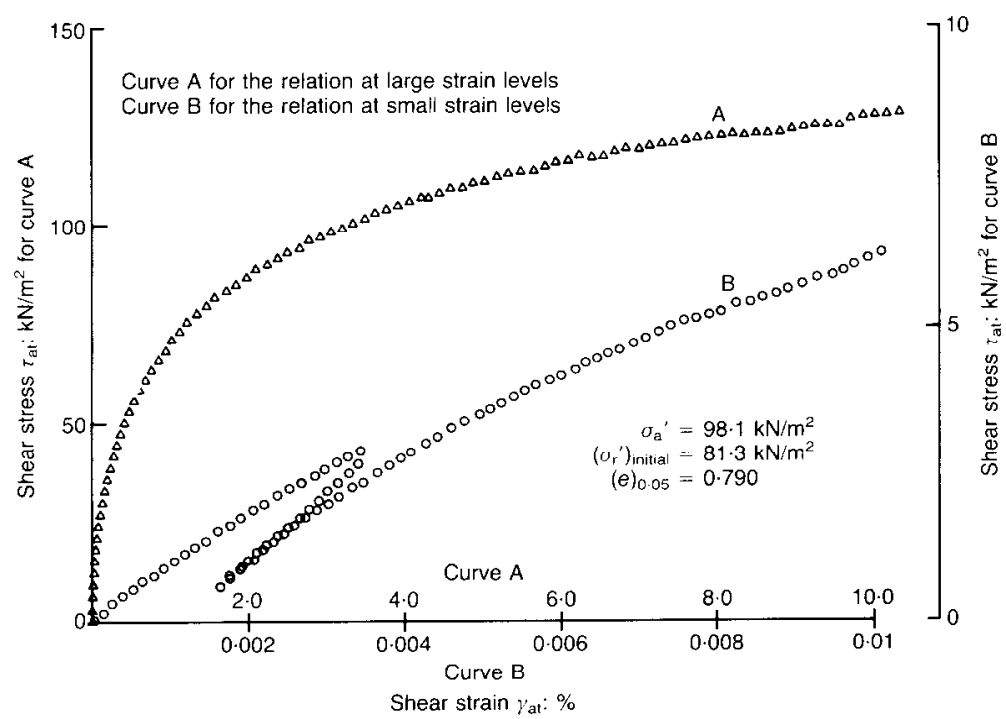

Fig. 14. Shear stress-shear strain relationships for maximum scales of shear strain of (A) $10 \%\left(10^{-1}\right)$ and (B) $0-01 \%\left(10^{-4}\right)$ observed in a monotonic loading torsional simple shear test on Toyoura sand 


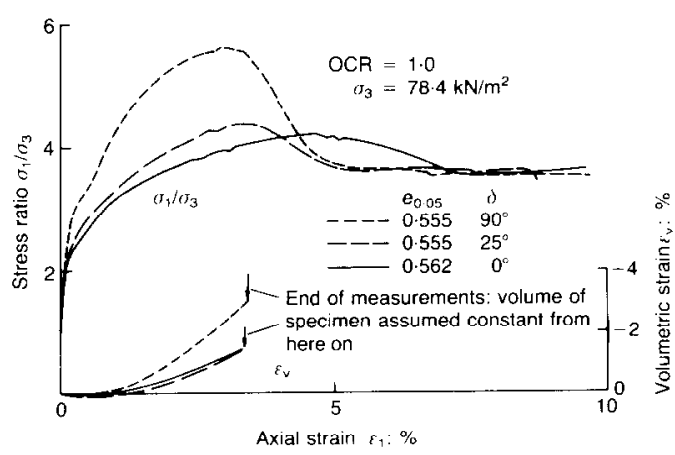

(a)

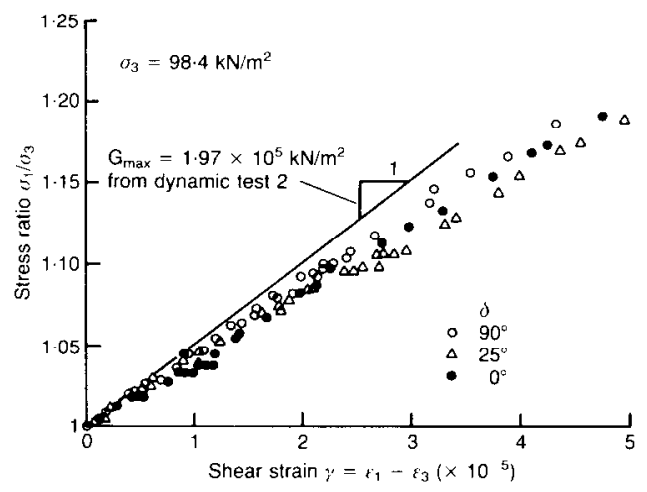

(b)

Fig. 15. Relationships (a) between the stress ratio and the axial strain to $10 \%\left(10^{-1}\right)$ and (b) between the stress ratio and the shear strain to $0005 \%\left(5 \times 10^{-5}\right)$ observed in PSC tests on silver Leighton Buzzard sand

virgin specimen (or on a pre-sheared specimen), the value would be similar to that of $G_{\max }$ of the corresponding RC test shown in Fig. 2.
Finally, with respect to stiffness at strains below $0.01 \%\left(10^{-4}\right)$, it may be seen from Fig. 13 that the strain dependency is much greater for the ML TSS test (curve 1) than in the RC and SCL tests (curves 2, 3 and 4). This means that while $G_{\max }$ can be evaluated from ML tests, the secant shear moduli $G_{\text {sec }}$ as a function of shear strain level have to be evaluated separately for monotonic and cyclic loading conditions.

It is stated in the Paper that "both the model and the experimental data show that the variation in the resonant frequency (i.e. the stiffness of specimen) is still significant at shear strain amplitudes below $0.01 \%\left(10^{-4}\right)$ ' and 'the variation of the resonant frequency is apparent even at small strains'. This tendency can also be seen in the relationships between curves 2, 3 and 4 (Fig. 13), but not to any great extent. Therefore, if the Authors' data in Figs 2, 8, 9 and 10 are examined in a similar manner as shown in Fig. 13 (i.e. in the relationship between the secant shear modulus $G_{\mathrm{sec}}$ and the logarithm of single amplitude shear strain $\log \gamma$ ), and if they are compared with those of Toyoura sand, the dependency of the stiffness for strains below $10^{-4}$ may be better evaluated in a quantitative manner.

\section{ACKNOWLEDGEMENT}

We are indebted to Professor J. R. F. Arthur of University College, London, for providing us with silver Leighton Buzzard sand.

\section{Authors' reply}

It is valuable to have the corroboration from Tatsuoka et al. of the possibility of recovering dynamic soil stiffnesses from static soil tests, and most interesting to appreciate that this assump-

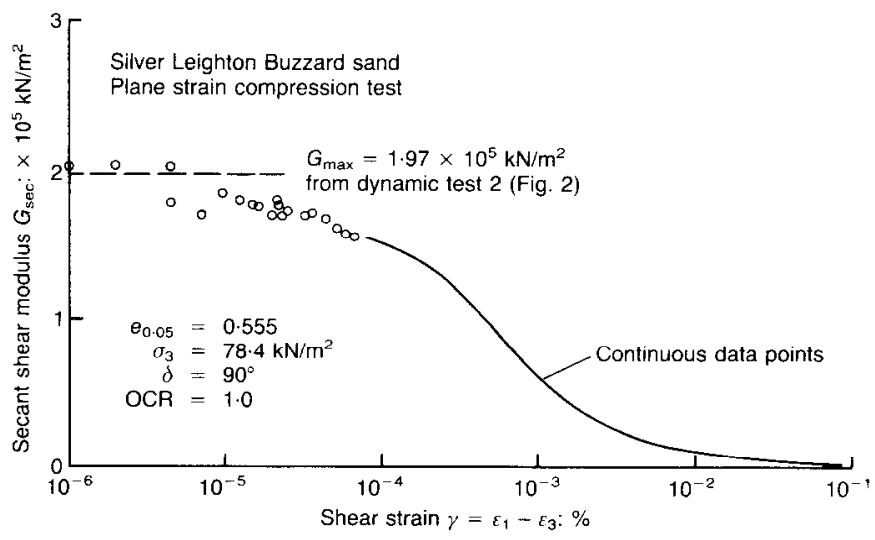

Fig. 16. Secant shear modulus-shear strain relationship in a PSC test at $\delta=90^{\circ}$ on silver Leighton Buzzard sand 
tion underpins the Japanese approach to the analysis of earthquake response. Some of the particular advantages of performing slow, cyclic tests rather than resonant-column tests are brought out clearly in their discussion. Sample preparation may permit the simulation of various anisotropic conditions arising either from bedding planes or from the effects of consolidation history. Furthermore, the development of a progressively stiffer response, cycle by cycle, is effectively available only in slow cyclic tests such as those shown in Fig. 13 or in Fig. 3. Backanalysis of the initial data of increasing response over the first few tens of cycles in resonantcolumn tests, even where rates of sampling were sufficient, is impeded by the complex interaction between the applied excitation and the inertia of the top cap.

We agree that the available data suggests that the small-strain modulus $G_{\max }$ may be estimated equally from static or dynamic tests, but only when there has been strain reversal. Tests based on the propagation speed of waves, or on the achievement of steady resonance, clearly satisfy the reversal condition. Monotonic tests do not necessarily follow a reversal of the major principal strain direction however, and neither does soil in the field. Soil in the field will generally have been deposited, buried and partially unloaded. Its initial state, in terms of mobilized shear stress and strain, will be analagous to the soil at some point on the unload-reload loop in Fig. 14. An initial response at $G_{\max }$ will be followed by a resumption of a modulus degrading not from the start of the latest episode of loading, but from the original shear strain origin.

Whereas resilient response only requires data from a single unload-reload loop, the prediction of total response requires knowledge of the whole strain history. It must not be forgotten by those using data such as in Figs 13 or 16, that the strain origin is vital to their prediction. In this context, even previous one-dimensional compression must be recognized as causing shear strain (equal to the volumetric strain, in that case). In the general case, only that stress increment which causes a strain reversal can generate a stiff $G_{\max }$ response.

In our own torsion tests it was found to be difficult to exclude a small torsion cycle when fixing the top cap before testing, thus causing the initial modulus to take the value $G_{\max }$. We believe that the same effect can be scen in the first threc data points in Fig. 14 -perhaps the true virgin stiffness is represented by the gradient of points four to six, which is only about $0.5 G_{\max }$. We therefore believe that a distinction must be drawn between data of monotonic virgin loading and data of stress amplitude plotted against strain amplitude for the steady hysteretic response of soil which has been subjected to a number of identical cycles - the backbone curve defined in the Paper. There seems to be no good reason to assume that the two curves share the same initial gradient.

Regarding stiffness at strains below $10^{-4}$, we agree that the dependency of $G$ on $\gamma$ is much reduced, compared to the reductions evident at $\gamma>10^{-4}$. Apparently, however, the dependency at $\gamma=10^{-4}$ is still sufficient to produce the asymmetrical frequency response curve which we now know is symptomatic of hysteretic materials. There is extreme sensitivity to frequency of excitation just below resonance. This fact may yet prove to be important to the design of foundations for extremely sensitive equipment. The extra accuracy provided by the new apparatus of Tatsuoka et al. and displayed in Figs 13 and 16 suggests that for shear strains smaller than $10^{-6}$ sands will behave as elastic materials with negligible material damping. If a client were to impose a

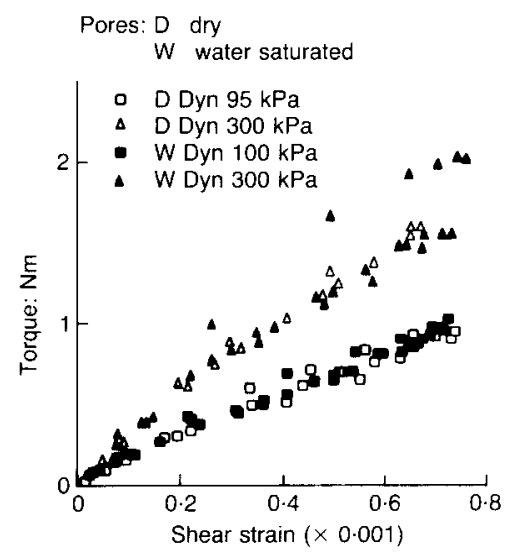

Fig. 17. Dynamic torsion data

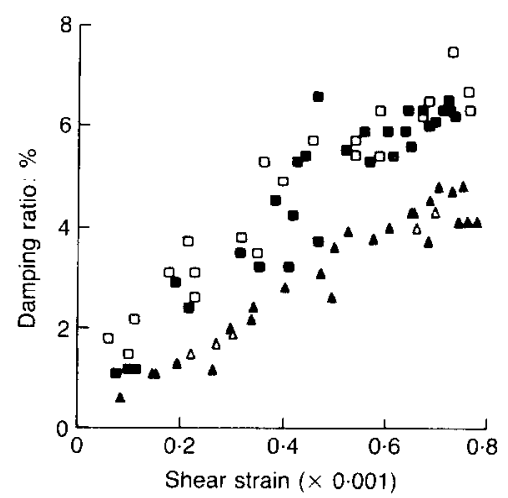

Fig. 18. Dynamic damping data 
rotation limitation of this order of magnitude as a performance criterion, the engineer would have even greater anxiety about the possibility of resonance. We hope that our association of material damping with the decline of shear modulus due to shear strain, using only a hysteresis loop on a stress-strain diagram, will encourage a more rational selection of damping ratio in dynamic analysis.

The use of a hysteretic stress-strain relation for soil, with zero viscosity even when the soil is saturated, is supported by the data of stiffness and damping for dry and water-saturated sand shown in Figs 17 and 18. The presence of pore water has no effect on the soil parameters at a given effective stress level, although the possibility that effective stress might fall due to the creation of excess pore pressures must be addressed separately. Figs 17 and 18 support the Japanese working hypothesis that soil parameters for earthquake analysis can be derived from convenient static tests. We hope to conduct further work so that proper limits can be placed on the neglect of fluid viscosity and other effects of strain rate, relevant perhaps to very high frequency vibrations in water-saturated sands or to earthquakes in tar sands or clays.

\section{REFERENCES}

Kokusho, T. (1980). Cyclic triaxial test on dynamic soil properties for wide strain range. Soils \& Fndns 20, No. 2, 45-60.

Park, C. S. (1990). Anisotropy in deformation and strength properties of sands in plane strain compression tests. Master of Engineering thesis, University of Tokyo.

Pradhan, T. B. S., Tatsuoka, F., \& Horii, N. (1988). Simple shear testing in a torsional shear apparatus. Soils \& Fndns 28, No. 2, 95112.

Shibuya, S., Tatsuoka, F., \& Kong, X. J. (1990). Discussion: Recent developments in laboratory strength and deformation testing, Proc. 12th Int. Conf. Soil Mech. \& Fndn Engng, Rio de Janeiro, 4.

Tatsuoka, F. (1988). Some recent developments in triaxial testing systems for cohesionless soils. Advanced Triaxial Testing of Soils \& Racks, 977, 7-67.

Tatsuoka, F., Pradhan, T. B. S., \& Yoshi-le, H. (1989). A cyclic undrained simple shear testing method for soils. Geotech. Testing Journal, 12, No. 4, 269-280.

Totsuoka, F., Shibuya, S., Goto, S., Sato, T., \& Kong, X. J. (1990). Discussion on Paper by Clayton et al. Geotech. Testing Journal 12, No. 1, 69-76.

Teachavorasinskun, S. (1989). Stress-strain and strength characteristics of granular materials in simple shear. Master of Engineering thesis, University of Tokyo.

Wong, R. K. S., \& Arthur, J. R. F. (1985). Induced and inherent anisotropy in sand. Géotechnique 35, No. 4, 471-481. 